of essential hypertension and would be some evidence in favour of a primary disorder of the central nervous system. Therefore the careful study reported by A. R. Lorimer ${ }^{3}$ and his colleagues from Glasgow Royal Infirmary merits close consideration. These authors examined a small series of 15 normal and 15 hypertensive persons of comparable age and subjected them to a standardized emotional stress. This involved sorting ball-bearings while concentration was made difficult by discordant noise and by variations in the intensity of lighting. The authors measured the blood pressure and also the hourly excretion rate of adrenaline and noradrenaline in the urine before, during, and after the application of this standardized stress for one hour. In respect of blood pressure response the authors confirmed the results of most previous studies. The normal group with blood pressures of about $112 / 80 \mathrm{~mm} \mathrm{Hg}$ showed a rise to approximately $126 / 90$ during the emotional stress. The hypertensive group, starting at approximately 164/102 $\mathrm{mm} \mathrm{Hg}$, showed a rise of blood pressure during the procedure to approximately $192 / 118$. Thus the hypertensive group showed a larger absolute and a larger relative rise of blood pressure during mental stress. However, the excretion rates of adrenaline and noradrenaline in the urine were closely comparable in the two groups. The initial resting (pre-stress) values for excreted adrenaline and noradrenaline were virtually identical in the two groups (a finding that confirms many other reported observations). For both men and women the rise of adrenaline was slightly greater in the hypertensive than in the normal group, but the differences were not significant, and for noradrenaline no consistent change was seen.

Though this study was made on a rather small group of patients, inspection of the authors' figures does not suggest that the results would be greatly different even if it had been a very much larger one. How can the results best be interpreted? Since the increased response of hypertensives was not associated with a corresponding increase in urinary excretion of catecholamines, the abnormal rise in blood pressure cannot easily be attributed to an increased secretion rate of catecholamines in response to stress in these patients. It could be due to an excessive response to normal amounts of vasopressor material. However, it has been reported ${ }^{4}$ that hypertensive people also have a higher than normal rise of pressure in response to a variety of stimuli, and therefore the increased "responsiveness" of the hypertensive might be an entirely non-specific effect of narrowed arterioles, producing a proportionately larger rise in peripheral resistance and in blood pressure when they were stimulated to constrict by a standard stress, whether locally applied or coming through the nervous system. Lorimer and his colleagues' results are certainly in keeping with this hypothesis.

Nevertheless, any interpretation of such findings needs to be cautious. The chief problem arises because of the extraordinarily small amounts of adrenergic transmitter liberated into the blood stream with increased nervous activity. Most noradrenaline is reincorporated into nerve endings, and much of the remainder is destroyed by local enzymes before it leaves the tissues. Furthermore, such catecholamines as do escape into the general circulation are metabolized quite rapidly, and it has been calculated that only about $1-3 \%$ of an intravenously infused dose actually passes into the urine. ${ }^{5}$ Therefore the secretion rate even of adrenaline (which is a hormone presumably designed to act through the blood stream) can only be approximately assessed by study of urinary excretion. We are condemned to make inferences about sympathetic nervous activity from measurement of urinary noradrenaline when urinary noradrenaline itself constitutes only about $0.1 \%$ of that actually liberated at adrenergic neurones. This is not to say that such studies do not provide evidence against any increase of basal neurogenic tone, or of increased sympathetic activity in response to "stress," but we need to remember that evidence provided by such means is slim and could be vitiated entirely if it were confirmed that the rate of reincorporation or metabolism of noradrenaline in hypertensive patients was very slightly different from that in normal persons. ${ }^{6}$

However, the phenomenon might have some clinical importance, whatever its cause. John Hunter is reputed to have predicted that his life was at the mercy of any fool who provoked him, and he is reported to have died suddenly after some bitter argument. It is well to remember that the classic hypertensive patient in a consulting room, whose blood pressure is only mildly raised after some minutes' rest, and for whom a conservative physician might reasonably decide that hypotensive therapy was not necessary, might be very different in a stressful situation. If his response to an emotional stress was greater than that provided by sorting ball-bearings under difficult conditions, we should perhaps think of such a patient as needing special protection against the possibly disastrous effects of a family quarrel. This might be a reason for prescribing hypotensive drugs such as propranolol, which has given several physicians the impression of reducing fluctuations of blood pressure in response to stress. Designers of future trials of hypotensive agents might usefully consider including a formal test of the ability of different drugs to reduce emotionally caused rises of blood pressure.

\footnotetext{
1 Sivertsson, R., Acta Physiologica Scandinavica, 1970, Supplement No. 343 .

2 Nestel, P. J., Lancet, 1969, 1, 692.

Lorimer, A. R., Macfarlane, P. W., Provan, G., Duffy, T., and Lawrie, T. D. V., Cardiovascular Research, 1971, 5, 169.

Shapiro, A. P., Moutsos, S. E., and Krifcher, E., fournal of Clinical Investigation, 1963, 42, 1890 .

Von Fuler, U. S., Luft, R., and Sundin, T., Acta Physiologica Scandinavica, $1953,30,249$.

${ }^{6}$ Gitlow, S. E., et al., fournal of Clinical Investigation, 1964, 43, 2009.
}

\section{Lobar Obliterative Bronchiolitis}

Abnormal transradiancy of one lung or lobe, in the absence of a technical or extrapulmonary cause, is sometimes observed. It commonly results from unilateral bullous emphysema, or less often from emphysema secondary to a valvestenosis or partial block in a large bronchus. On rarer occasions these commoner factors are absent and the localized emphysema appears under a variety of headings -among them congenital bronchiectasis, ${ }^{1}$ cystic lung, ${ }^{2}$ pulmonary hypoplasia, ${ }^{3}$ solitary lobar atrophy, ${ }^{4}$ and unilateral emphysema. 5

In 1952 W. M. Macleod focused attention on this disease group and described the main features. ${ }^{6}$ These are decreased breath sounds over the involved lobes, increased radiographic transradiancy, normal bronchoscopy, and a relatively normal bronchial tree on bronchography, though there may be some irregularity of bronchial calibre and usually decreased or absent "alveolar filling." This last bronchographic feature we now recognize as absent "millimetre pattern" at the site of the terminal bronchioles. ${ }^{7}$ The affected lung or lobe always shows evidence of obstructive 
emphysema in addition to decreased perfusion, and a number of physiological studies have confirmed these features.

The explanation of this abnormal development has been the subject of much conjecture and little evidence. Macleod originally postulated that the lung was irreparably damaged during the growing period, resulting in distended dwarflike lobes. He commented on the evidence of severe past primary tuberculous infection in similar cases but excluded these from his main series. He also noted the resemblance between this select group and those with unilateral bronchiectasis and associated emphysema. There is now growing confirmation of these postulates that the damage originates in childhood infections, usually pneumonic but occasionally following primary tuberculous infection. ${ }^{8} \mathrm{G}$. R. Cumming and his colleagues record the development of this emphysema in five children after pneumonia, in three of whom viral studies suggested adenovirus as the possible agent. ${ }^{9}$

The basic lesions are multiple peripheral obstructions at bronchiolar level, an obliterative bronchiolitis. It is no longer reasonable to distinguish this from the same process developing in the lobular bronchi, obliterative bronchitis. ${ }^{8}$ Why then is the disease unilateral? Firstly, unilaterality was one of the criteria used in the original selection of material. Secondly, pneumonia, if it is the precursor, often is unilateral. Thirdly, if the disease is truly bilateral, such severe damage is incompatible with life. Fourthly, the same disease process has been recognized as affecting some lobes or segments of both lungs. Finally, obliterative bronchiolitis may present in a scattered lobular form throughout both lungs, appearing as generalized obstructive airways disease in childhood or later life and masquerading superficially as resistant chronic asthma. ${ }^{10}$ The unilaterality is a false distinction, and terms such as "Macleod's syndrome" should now be abandoned and replaced by lobar bronchiolar obstruction with emphysema.

While the accumulating evidence strongly favours the view that the lobar disease follows early childhood infection, some investigators suggest that the predisposing factor is a congenital hypoplasia of the pulmonary artery. ${ }^{11}$ While this may explain the transradiancy with decreased perfusion, it overlooks the obstructed ventilation, unless it is assumed that such defective perfusion leads to unilateral airways obstruction. Pulmonary embolic occlusion may temporarily result in acute asthmatic bronchoconstriction, ${ }^{12}$ but there is no evidence that such decreased pulmonary perfusion leads permanently to irreversible bronchiolar obstruction. In patients with congenital absence of one pulmonary artery the lung may be abnormally transradiant, but the ventilation is little affected. ${ }^{13}$

The damaged lung, once recognized, generally shows little change over the years of recorded observation. It is a poor organ for respiration, but it rarely if ever interferes with the function of the opposite lung, though the originating disease may well have damaged it also at the same time. The diseased lung has, however, a useful space-filling function and therefore should be left alone. There is no place for surgical resection unless, as rarely occurs, the lung is the site of troublesome recurrent bacterial infection or, more rarely, is the seat of a lung cancer. Once the diagnosis has been reasonably established, too much attention, as with any uncorrectable deformity, may cause the patient needless worry.

1 Herms, J., and Mumme, C., Beiträge zur Klinik der Tuberkulose und spezifischen Tuberculose-Forshung, 1931, 77, 701.

- Sellors, T H., Tubercle, 1938-39, 20, 49 and 114

s Field, C. E., Archives of Disease in Childhood, 1946, $21,61$.
4 De Martini, A., Minerva Medica, 1948, 39, 238

${ }^{5}$ Swyer, P. R., and James, G. C. W., Thorax, 1953, 8, 133.

6 Macleod, W. M., Thorax, 1954, 9, 147.

Reid, L., and Simon, G., Thorax, 1958, 13, 103.

Reid, L., The Pathology of Emphysema. London, Lloyd-Luke, 1967.

Cumming, G. R., Macpherson, R. I., and Chernick, V., fournal of Pediatrics, 1971, 78, 250.

${ }^{10}$ Box, C. R., Lancet, 1933, 1, 1271.

Belcher, J. R., Capel, L., Pattinson, J. N., and Smart, J., British fournal of Diseases of the Chest, 1959, 53, 253.

12 Sasahara, A. A., and Stein, M., Pulmonary Embolic Disease, New York, Grune and Stratton, p. 162. 1965.

13 Massumi, R. A., and Donohoe, R. F., Circulation, 1965, 31, 436.

\section{Retrorectal Tumours}

In conducting a digital examination of the rectum the clinician is so accustomed to feeling primarily for something in the bowel itself or lying anterior to it-for example, in the prostate, uterus, or pelvic peritoneum-that it almost requires a conscious effort of will to palpate with the same thoroughness in a posterior direction. The conditions that may be encountered as retrorectal "tumours" are rare, so that it is good for the average surgeon to be reminded of their varied nature and characteristic features by periodical reviews of large collective series of cases, ${ }^{1-4}$ the most recent being a report by D. T. Freier and his

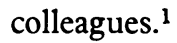

Retrorectal swellings may be inflammatory, due to inadequately draining anorectal abscesses and fistulas, to barium that has escaped through a tear in the rectal wall during a barium enema examination, ${ }^{5}$ or even to entrance of phenol and oil into the perirectal tissues during a badly given injection for haemorrhoids. Another group comprises ordinary soft tissue tumours, such as lipomas, liposarcomas, fibromas, fibrosarcomas, haemangiomas, neurofibromas, and neurolemmomas. A third group consists of bony tumours affecting the sacrum and coccyx; these include primary osteosarcomas and chondrosarcomas, giant cell tumours and bone cysts, and bony metastases from visceral carcinomas. But unquestionably the commonest retrorectal tumours are congenital lesions-teratomas, dermoid cysts, and chordomas.

Teratomas are initially encapsulated cystic or solid tumours containing a mixture of tissues. Though largely confined to infants, a few have been recorded in adults, ${ }^{6} 12 \%$ of them being malignant. Superadded infection is common and may mask the underlying condition. Moreover, the tumour may burst into the rectum. $X$-ray examination may be helpful in diagnosis by showing bone formation or teeth. Because of their tendency to become infected and to rupture, teratomas should be excised if possible. Usually this can be done through a sacral incision, but occasionally an abdominal or abdomino-perineal approach is required. If the lesion is benign and is removed intact the prognosis is excellent. Incomplete removal results in recurrence. The outlook with malignant teratomas is also poor.

Dermoid cysts are presumably due to a faulty inclusion of ectoderm when the embryo coalesces. Usually they do not appear till adult life and are much more common in women than men. They may be unilocular or multilocular and vary in size from an average diameter of $2-5 \mathrm{~cm}$ up to $10 \mathrm{~cm}$. They are prone to be complicated by infection and may thus be confused with ordinary anorectal abscesses and fistulas. The prognosis as to life is excellent, but recurrence after operation is not infrequent because of incomplete removal owing to the size of the lesion or its adherence to surround- 